\title{
Cassava common mosaic virus infection causes alterations in chloroplast ultrastructure, function, and carbohydrate metabolism of cassava plants
}

\author{
Andrea A. Zanini ${ }^{1,2}$ (D) | Liliana Di Feo ${ }^{3,4}$ | Dario F. Luna ${ }^{1,2}$ | Pablo Paccioretti ${ }^{4,5}$ | \\ Agostina Collavino $^{6}$ | Marianela S. Rodriguez ${ }^{1,2}$ (C)
}

${ }^{1}$ Instituto de Fisiología y Recursos Genéticos Vegetales, Centro de Investigaciones Agropecuarias-INTA, Córdoba, Argentina

${ }^{2}$ Unidad de Estudios Agropecuarios (UDEA), INTA - CONICET, Córdoba, Argentina

${ }^{3}$ Instituto de Patología Vegetal, Centro de Investigaciones Agropecuarias-INTA, Córdoba, Argentina

${ }^{4}$ Unidad de Fitopatología y Modelización Agrícola (UFyMA), INTA - CONICET,

Córdoba, Argentina

${ }^{5}$ Cátedra de Estadística y Biometría, Facultad de Ciencias Agropecuarias, Universidad Nacional de Córdoba, Córdoba, Argentina

${ }^{6}$ Facultad de la Producción y del Medio Ambiente, Instituto Universitario de Formosa, Centro de Investigación y Transferencia de Formosa - CONICET, UNaF, Formosa, Argentina

\section{Correspondence}

Marianela S. Rodriguez, Instituto de Fisiología y Recursos Genéticos Vegetales, Centro de Investigaciones AgropecuariasINTA, Av. 11 de Septiembre 4755, X5020ICA, Córdoba, Argentina.

Email: rodriguez.marianela@inta.gob.ar

Funding information

Fondo para la Investigación Científica y Tecnológica, Grant/Award Number: PICT 2014-551; Instituto Nacional de Tecnología Agropecuaria, Grant/Award Number: 1085; Consejo Nacional de Investigaciones Científicas y Técnicas

\begin{abstract}
Cassava common mosaic virus ( $\mathrm{Cs} C \mathrm{CMV}$ ) is a potexvirus that causes systemic infections in cassava plants, leading to chlorotic mosaic and producing significant yield losses. To date, the physiological alterations and the mechanism underlying biotic stress during the cassava-CsCMV compatible interaction remains unknown. In this study, we found that CsCMV infection adversely modified chloroplast structure and had functional effects on chloroplasts in source leaves during the course of viral infection. Extrusion of the chloroplast membrane with amoeboid-shaped appearance and disorganized grana stacks were observed in infected mesophyll cells. These alterations were associated with up to $35 \%$ reduction of relative chlorophyll content, and a decline of $\mathrm{CO}_{2}$ fixation ( $13.5 \%$ and $24.2 \%$ at 90 and 210 days after planting, respectively). The effects of $\mathrm{CsCMV}$ infection on the performance index on absorption basis dropped up to $37 \%$. The analysis of chlorophyll $a$ fluorescence showed a progressive loss of both oxygen evolving complex activity and "connectivity" within the tripartite system (core antenna-LHCII-reaction centre). Here, we report the latter phenomenon for the first time in a viral infection. The oxidative stress process was observed in CsCMV-infected plants (20.8\% reduction of antioxidant capacity with respect to noninfected plants). Other effects of the pathogen included reduction of starch and maltose content in source leaves, and a significant increase (24.7\%) of the sucrose:starch ratio, which indicates an altered pattern of carbon allocation. Our results suggest that $\mathrm{CSCMV}$ induces chloroplast distortion associated with progressive chloroplast function loss and diversion of carbon flux in source leaf tissue, leading to the loss of cassava tuber yield.
\end{abstract}

KEYWORDS

biotic stress, cassava, chloroplast alteration, CsCMV, OJIP test, potexvirus

\section{1 | INTRODUCTION}

Cassava (Manihot esculenta) is one of the most widely grown tuber crops and an important food security crop for smallholder farmers, especially in low-income, food-deficit areas (FAO, 2013). Its storage roots are the main organ, which are marketed as a feed resource and feedstock for starch extraction, bioenergy production, and pharmaceutical and textile industries. Accordingly, cassava is a widely 
recognized sustainable crop in the context of the global changing climate (FAO, 2013; Marx, 2019). Its productivity is conditioned by the starch accumulation from $\mathrm{CO}_{2}$ fixation and the source-sink relationship (Yan et al., 2019). Because cassava is vegetatively propagated, its yield is greatly restrained by viral diseases (Legg et al., 2015). Among all reported cassava-infecting potexviruses (Lozano et al., 2017), cassava common mosaic virus (CsCMV) has been identified as the only one able to cause disease in a single infection and to produce significant yield losses (Venturini et al., 2016; Zanini et al., 2020). This pathogen has been detected infecting cassava crops in South America (Chaparro-Martinez and Trujillo-Pinto, 2003; Silva et al., 2011; Calvert et al., 2012; Fernandez et al., 2017; Zanini et al., 2018) and recently in China (Tuo et al., 2020).

The typical symptoms of CsCMV infection, known as cassava common mosaic disease, vary in severity and include a wide range of foliar chlorotic mosaic (light green chlorotic areas, interspersed with dark green areas), sparsely distributed in the leaf blade of cassava plants (Zanini et al., 2018). These kinds of symptoms might be the consequence of chloroplast deformation and impairment induced by the virus infection (Li et al., 2016a; Zhao et al., 2016). For example, viruses interfere with photochemical reactions by reducing the abundance of key proteins involved in the photosynthetic electron transport chain (Souza et al., 2019, and references therein). In this context, alterations in electron transport might generate reactive oxygen species (ROS), which affect the cellular redox state (Rodríguez et al., 2010). A wide range of physiological and biochemical disorders are triggered from cell infection, including relocation of photoassimilates, redox imbalance, and premature senescence, with significant economic losses (Rodríguez et al., 2010, 2012; Souza and Carvalho, 2019). Viral infections lead to a decline in $\mathrm{CO}_{2}$ fixation, which could be directly related to a decrease in carbohydrate accumulation, reducing plant growth and development (Sade et al., 2013; Nuwamanya et al., 2017). In contrast, other studies have demonstrated that soluble sugars and starch accumulate in the infected leaves, where photosynthesis is reduced (Rodríguez et al., 2010; Andreola et al., 2019). Furthermore, abnormal accumulation or depletion of starch in systemically infected tissues was reported in cucumber mosaic virus (CMV)-marrow interaction (Técsi et al., 1996). Therefore, the mechanisms associated with changes in carbohydrate metabolism are specific to the plant-virus pathosystem. To our knowledge, the effect of CsCMV infection on sugar and starch content has not yet been studied.

Given the significant yield losses caused by CsCMV (from 30\% to 60\%; Venturini et al., 2016; Zanini et al., 2020), it is imperative to investigate the physiological basis underlying cassava-CsCMV interplay, which remains unknown. Previous studies by Tascon et al. (1975) described filamentous particles, of varied size and shape, in the cytoplasm of CsCMV-infected cells in different plant species. Accordingly, our previous results showed inclusion bodies of fibrous masses containing filamentous particles in the cellular cytoplasm near the chloroplast membrane (Zanini et al., 2014). Here, we focused our research on chloroplast morphological and functiona alteration of cassava leaves. Taking into account the theoretical background mentioned above, we hypothesized that CsCMV would induce anomalies in the chloroplasts associated with reduced photosystem II (PSII) electron transport activity and redox imbalance. We further proposed that because $\mathrm{CO}_{2}$ fixation decreases, sugar and starch content will be negatively affected. Therefore, the present study provides, for the first time, information about chloroplast structure and progression of cassava common mosaic disease on chloroplast function in the compatible cassava-CsCMV interaction.

\section{MATERIALS AND METHODS}

\section{1 | Generation of plant material}

Twenty in vitro-grown, healthy cassava cv. ICA Negrita (CM33064) plants were used. Sixty days after acclimation, 10 plants were graft-inoculated with budwood from CsCMV-affected cassava plants (CsCMV isolate GenBank accession number KY445966) and the other 10 were autografted to maintain their healthy condition. Yellowing and blotchy mosaic symptoms were visible 20 days after inoculation. These plants were analysed by double antibody sandwich (DAS)-ELISA specifically for CsCMV detection (detailed below) and then transplanted in the field for macropropagation and as a source of stem cuttings for subsequent greenhouse trials.

\subsection{Experimental setup}

Cassava plants were propagated clonally from segments with at least six nodes (approximately $20 \mathrm{~cm}$ in length) of the plants mentioned above. The plants were grown individually in plastic pots $(3 \mathrm{~L})$ containing a 3:1 mixture ( $\mathrm{vol} / \mathrm{vol})$ of potting soil and sand mixture, in a naturally illuminated greenhouse. All experiments were carried out in summer (average temperature $28 \pm 5^{\circ} \mathrm{C}$ ). A randomized design was conducted with two treatments (healthy and CsCMV-infected cassava plants) arranged in three blocks, with 10 replicates per block and treatment $(N=60)$. These plants were used for the measurements of all the parameters described below.

\section{3 | Plant growth measurement}

Measurements of number of nodes and number of leaves per bud were taken in 30 noninfected (control) and 30 CsCMV-infected plants at three ontological stages; 60,75 , and 90 days after planting (DAP) of cassava plants, encompassing the key stages of cassava growth, from the young stage (cassava plants that start from stem cuttings, until $60 \mathrm{DAP}$ ) to the formation of root system (until 110 DAP). Plant height was measured at 60, 75, 90, and 210 DAP (cassava growth stage of starch maturity).

Leaf tissue samples, excluding petioles, were taken from the fourth leaf (counting from the base to the top) of each plant at 90 DAP. They were immediately frozen in liquid nitrogen and stored at 
$-80^{\circ} \mathrm{C}$ for subsequent biochemistry determinations. These leaves represent a source organ.

\subsection{Serological virus detection}

CsCMV was detected by DAS-ELISA performed in polystyrene microtitre plates with anti-CsCMV-IgG as described Zanini et al. (2018). All noninfected and CsCMV-infected cassava plants were tested.

\section{5 | Transmission electron microscopy and immunogold labelling}

Small tissue sections $(0.2 \mathrm{~cm}$ wide $\times 0.5 \mathrm{~cm}$ long) sliced from the middle part of CsCMV-infected leaves were fixed in $2 \%$ paraformaldehyde and $2 \%$ glutaraldehyde in $0.01 \mathrm{M}$ phosphate buffer, $\mathrm{pH} 7.2$, for 1 day. Then, they were postfixed in $1 \% \mathrm{OsO}_{4}$ in the same buffer and embedded in LRGold, as previously described (Maunsbach and Afzelius, 1998). Ultrathin sections ( $80 \mathrm{~nm}$ ) were cut with a diamond knife using an ultramicrotome and collected onto nickel grids. For transmission immunoelectron microscopy (TEM), sections mounted on nickel grids were preincubated with $1 \%$ bovine serum albumin (BSA) in 1\% phosphate-buffered saline (PBS) overnight, and then treated with specific antiserum anti-CsCMV (Zanini et al., 2018) for $6 \mathrm{hr}$. The sections were then exposed to gold-conjugated protein A of $5 \mathrm{~nm}$ in diameter (Zymed). Sections from uninfected cassava leaves were used as additional controls in the immunolabelling experiments. They were examined under a JEM-1200 transmission electron microscope (JEOL).

\subsection{Chlorophyll content, chlorophyll $a$ fluorescence, and gas exchange measurements}

\subsection{1 | Chlorophyll content}

The relative chlorophyll (Chl) content was determined with a SPAD meter (Hansatech chlorophyll content meter CL-01), using dual wavelength optical absorbance measurements (620 and $940 \mathrm{~nm}$ ). The measurements were taken simultaneously with chlorophyll $a$ fluorescence (ChIF), as described below. The SPAD index and ChIF were measured on the fourth leaf (counting from the base to the top) in 30 noninfected and $30 \mathrm{CsCMV}$-infected cassava plants, at three ontological stages (60,75, and 90 DAP). These measurements are widely used for rapid and nondestructive estimation of chlorophyll content and chloroplast function, respectively, in plant leaves.

\subsection{2 | Chlorophyll $a$ fluorescence transient}

ChIF emission was measured with a Pocket-PEA fluorometer (Plant Efficiency Analyzer, Hansatech Instruments Ltd). The polyphasic OJIP fluorescence kinetics was used to evaluate the PSII activity in CsCMVinfected and noninfected cassava plants. Before the ChIF measurement was taken, the fourth developed leaves were dark-adapted using leaf clips for at least $30 \mathrm{~min}$ in order to allow full oxidation of the reaction centres $(\mathrm{RC})$, to obtain the minimum fluorescence $\left(\mathrm{F}_{\mathrm{o}}\right.$ or $\mathrm{O}$ step) at approximately $50 \mu \mathrm{s}$. Then, an actinic 1-s light pulse of 3,500 $\mu \mathrm{mol}$ photons $\mathrm{m}^{-2} \cdot \mathrm{s}^{-1}$ was applied to reach the maximum fluorescence emission ( $F_{\mathrm{m}}$ or $\mathrm{P}$ step), at about $300 \mathrm{~ms}$. The intermediate steps, called J and I, were recorded at 2 and $30 \mathrm{~ms}$, respectively. The OJIP parameters were calculated using the Pocket-PEA manufacture software, following Strasser et al. (2004). The parameters are described in Table S1.

Changes in the oxygen evolving complex (OEC) activity and in the connectivity at PS II were calculated according to Chen et al. (2016). To reveal changes in OEC (Kband), fluorescence curves were normalized from the $\mathrm{O}$ to the $\mathrm{J}$ step, rendering $\mathrm{W}_{\mathrm{O}}$, curves. Next, $W_{O}$, curves from control plants were subtracted from treated ones $\left(\mathrm{W}_{\mathrm{OJ}(\text { Treated })}-\mathrm{W}_{\mathrm{OJ}(\text { Control) }}\right)$ to disclose the $\mathrm{K}$ bands $\left(\Delta \mathrm{W}_{\mathrm{O} \rho}\right)$. Positive values in these bands denote damage to the OEC. To detect $L$ bands, curves were normalized between 0 and $300 \mu \mathrm{s}$, and plotted as $\mathrm{W}_{\mathrm{OK}}$ curves. The subtraction between $\mathrm{W}_{\mathrm{OK}(\text { Treated) }}-\mathrm{W}_{\mathrm{OK}(\text { Control) }}$ was plotted to obtain $\Delta \mathrm{W}_{\mathrm{O}}$ curves, which allowed us to visualize $\mathrm{L}$ bands. The positive values of $\Delta \mathrm{W}_{\mathrm{O}}$ curves are proportional to the loss of connectivity at PS II.

\subsection{3 | Net photosynthesis rates}

Net $\mathrm{CO}_{2}$ assimilation rates were measured in the fourth fully expanded leaves of 30 noninfected and 30 CsCMV-infected cassava plants at 90 DAP, and 20 noninfected and 20 CsCMV-infected cassava plants at 210 DAP, with a portable photosynthesis system LI-6400 XT equipped with an LED leaf cuvette (Li-Cor). The concentration of $\mathrm{CO}_{2}$ inside the chamber was kept at $400 \mu \mathrm{mol} \mathrm{CO}_{2} /$ mol. The light source was set at saturating incident photosynthetic photon flux density (PPFD) of $1,500 \mu \mathrm{mol} \mathrm{m} \mathrm{m}^{-2} \cdot \mathrm{s}^{-1}$ (90\% of red and $10 \%$ of blue light) and the temperature was maintained at $25^{\circ} \mathrm{C}$.

\subsection{Determination of the effect of CsCMV on cassava carbohydrate}

\subsection{1 | Ethanolic leaf extract}

Frozen tissue $(75 \mathrm{mg}$ ) from source leaves of 30 noninfected and 30 CsCMV-infected cassava plants was ground with liquid nitrogen and cold homogenized with $750 \mu \mathrm{l} 80 \%$ ethanol. The extract was poured into a previously cooled microtube and centrifuged at $12,000 \times \mathrm{g}$ at $4^{\circ} \mathrm{C}$ for $10 \mathrm{~min}$. The samples were kept on ice and aliquots were separated to measure the total antioxidant capacity using ferric reducing ability of plasma (FRAP). The remaining extract was resuspended by vortex and incubated in a thermal bath at $80^{\circ} \mathrm{C}$ for $20 \mathrm{~min}$. The samples were then centrifuged at $12,000 \times \mathrm{g}$ at $4^{\circ} \mathrm{C}$ for $10 \mathrm{~min}$ and aliquots were separated from the 
supernatant to measure total sugars. The insoluble fraction was used for quantification of starch content.

\subsection{2 | Total soluble sugars}

Quantification of total soluble sugars was adjusted to a final reaction of $200 \mu \mathrm{l}$ in polystyrene plates. Ethanolic leaf extract and anthrone reagent ( $1 \mu \mathrm{l}$ each) were placed in each well. The blank contained water and anthrone reagent (Fales, 1951). The mixture was incubated at $4^{\circ} \mathrm{C}$ for $10 \mathrm{~min}$, then at $80^{\circ} \mathrm{C}$ for $30 \mathrm{~min}$, and subsequently allowed to cool for $20 \mathrm{~min}$ at room temperature. Glucose was used as standard to measure the total soluble sugars content, expressed as $\mathrm{mg}$ of glucose per $\mathrm{g}$ of fresh weight (FW).

\subsubsection{Starch content}

Starch content was determined in the pellet, from reducing sugars released after hydrolysis with the enzyme $\alpha$-amyloglucosidase (Sumner and Somers, 1944), using glucose as a standard. Starch content in the source organs was expressed as mg per $\mathrm{g}$ of FW of plant material.

\subsection{4 | Sugar determination}

Frozen source leaf samples ( $0.1 \mathrm{~g} \mathrm{FW}$ ) of 20 noninfected and 20 CsCMV-infected cassava plants were ground to a fine powder with liquid nitrogen, homogenized, and suspended in $0.9 \mathrm{ml}$ hot $80 \%$ ethanol, and kept at $80^{\circ} \mathrm{C}$ for $2 \mathrm{hr}$. Then, $0.9 \mathrm{ml}$ distilled water was added to each sample; samples were incubated at $99^{\circ} \mathrm{C}$ for $10 \mathrm{~min}$ and centrifuged at $12,000 \times \mathrm{g}$ for $5 \mathrm{~min}$. The supernatant was filtered using a nitrocellulose filtration membrane $(0.22 \mu \mathrm{m}$ pore size). Sucrose, glucose, fructose, and maltose were determined by high-performance liquid chromatography (HPLC; Shimadzu) using an amine column, isocratic acetonitrile:water (81:19) flow $(1 \mathrm{ml} / \mathrm{min})$, at $30^{\circ} \mathrm{C}$. Sugars were identified by their retention times and quantified according to standards.

\subsection{5 | ADP-glucose pyrophosphorylase activity}

The assay was performed in the reverse direction using phosphoglucomutase and glucose-6-phosphate dehydrogenase to couple glucose-1-phosphate formation in real time to $\mathrm{NADP}^{+}$reduction and then measured by spectrophotometer. The crude extracts were obtained from a total of 21 noninfected and 21 CsCMVinfected source leaves of cassava plants (the number of samples analysed per treatment and per block was seven leaves, one per plant) as described by Li et al. (2016b). Briefly, $0.1 \mathrm{~g}$ of fresh tissue was fully homogenized on ice in a $0.3 \mathrm{ml}$ precooled solution composed of $100 \mathrm{mM}$ HEPES- $\mathrm{NaOH}$ at pH 7.4, $8 \mathrm{mM} \mathrm{MgCl}_{2}, 2 \mathrm{mM}$ EDTA, $12.5 \%$ (vol/vol) glycerol, $5 \%$ (vol/vol) polyvinylpyrrolidone, and $50 \mathrm{mM} \beta$-mercaptoethanol. Then, a $20 \mu \mathrm{l}$ aliquot of the crude enzyme extract was used to start the assay, as detail by Li et al. (2016b). Absorbance values at $340 \mathrm{~nm}$ of the reaction solution were normalized by absorbance values at $340 \mathrm{~nm}$ resulting from the control. The ADP-glucose pyrophosphorylase (AGPase) activity was then estimated with the normalized absorbance values and was expressed in enzyme units per mg of protein, calculated according to Kulichikhin et al. (2016). Protein content was determined in leaf extracts by the Bradford (1976) assay.

\section{8 | Determination of total antioxidant capacity (FRAP)}

The FRAP assay was used to determine the total antioxidant capacity of the samples (Benzie and Strain, 1996); the protocol was adjusted for performance in a final reaction of $200 \mu \mathrm{l}$ in polystyrene plates. In each well, $2 \mu \mathrm{l}$ of ethanolic extract solution (see ethanolic leaf extract) were placed to react with FRAP reagent in the dark at room temperature for $20 \mathrm{~min}$ and the absorbance at $600 \mathrm{~nm}$ was recorded. Trolox (6-hydroxy2,5,7,8-tetramethylchroman-2-carboxylic acid; Sigma-Aldrich) solutions of known concentration, within in the range of 12.5 and $87.5 \mu \mathrm{M}$, were used for calibration. Total nonenzymatic antioxidant activity was measured on source leaves of 30 noninfected and $30 \mathrm{CsCMV-infected}$ cassava plants and was expressed as $\mu \mathrm{mol}$ per $\mathrm{g}$ of FW.

\section{9 | Statistical analysis}

Experiments were performed in a randomized design with two treatments: noninfected and CsCMV-infected cassava plants, arranged in three blocks, with 10 replicates per block and treatment $(N=60)$. Mixed linear model was performed using InfoStat (Di Rienzo et al., 2019). Mean separation was accomplished using Fisher's least significant difference (LSD) test at the 95\% confidence level.

\section{3 | RESULTS}

\subsection{Symptoms of CsCMV infection}

CsCMV-infected plants used in the experiments exhibited the typical symptoms of cassava common mosaic disease, such as foliar chlorotic mosaic and mild leaf distortion (Figure 1) with the appearance of the first leaf. Furthermore, those plants that were self-grafted remained symptomless and were used as control plants. Moreover, symptomless healthy control and systemic spread of the virus in leaves were confirmed by DAS-ELISA (data not shown). Even though viral infection showed conspicuous foliar mosaic, no differences in the fully expanded leaf area were observed between healthy $\left(56.77 \pm 4.56 \mathrm{~cm}^{2}\right)$ and CsCMV-infected $\left(58.96 \pm 4.44 \mathrm{~cm}^{2}\right)$ plants at 90 DAP (Figure S1). Yet growth analysis showed that viral infection significantly affected $(p<.05)$ the absolute and relative elongation rate (AER and RER, 
respectively, Figure $\mathrm{S} 2$ ). Indeed, the analysis of AER of infected plants showed a rapid stimulation of plant height (75-90 DAP; slope average of +0.27 in infected plants and +0.08 in noninfected ones), and subsequent decrease of the rate over the days with respect to noninfected plants (90-210 DAP; slope average of -0.17 for infected plants and +0.05 for control plants; Figure S2). The number of nodes and leaves per node increased over time; however, no significant differences were observed between plants of different sanitary conditions (Figure S3).

\subsection{CsCMV infection and chloroplast ultrastructure}

Differences between CsCMV-infected and control cells were compared and analysed in ultrathin sections of cassava leaves (Figure 2; Figure S4). The ultrathin sections of CsCMV-infected leaves revealed cytopathological effects on the chloroplast ultrastructure, which included dramatic chloroplast malformations, such as extrusion of the chloroplast membrane (stromule) with amoeboid-shaped appearance, irregular outer membrane structures, and small vesicles or vacuoles in the stroma. Moreover, partially destroyed and deformed chloroplasts with disorganized grana stacks and irregular arrangement of stroma lamellae was the most frequent feature of CsCMV-infected cells with respect to the healthy control (Figure 2). The noninfected chloroplasts exhibited regularly arranged grana stacks within chloroplasts (Figure S4).

Furthermore, CsCMV, as a potexvirus member, has flexuous filamentous particles of 470-580 nm in length, which were observed accommodated in inclusion bodies of fibrous masses, running more or less parallel to each other but not in a definite arrangement, in the cellular cytoplasm near the chloroplast membrane (Figure 2).

\subsection{Photosynthetic activity in CsCMV- infected leaves}

Fast ChIF kinetics analyses reflected alteration in the function of the PS II electron transport chain induced by CsCMV infection in cassava plants. The value of the OJIP parameters affected by CsCMV, at the three ontological stages (60, 75, and 90 DAP), were normalized to their respective control ones and plotted in a radar graph to deploy a global view of the structure and function of PS II electron transport (Figure 3b; Table S2). Accordingly, the maximum quantum efficiency $F_{v} / F_{m}$ was negatively affected as the disease
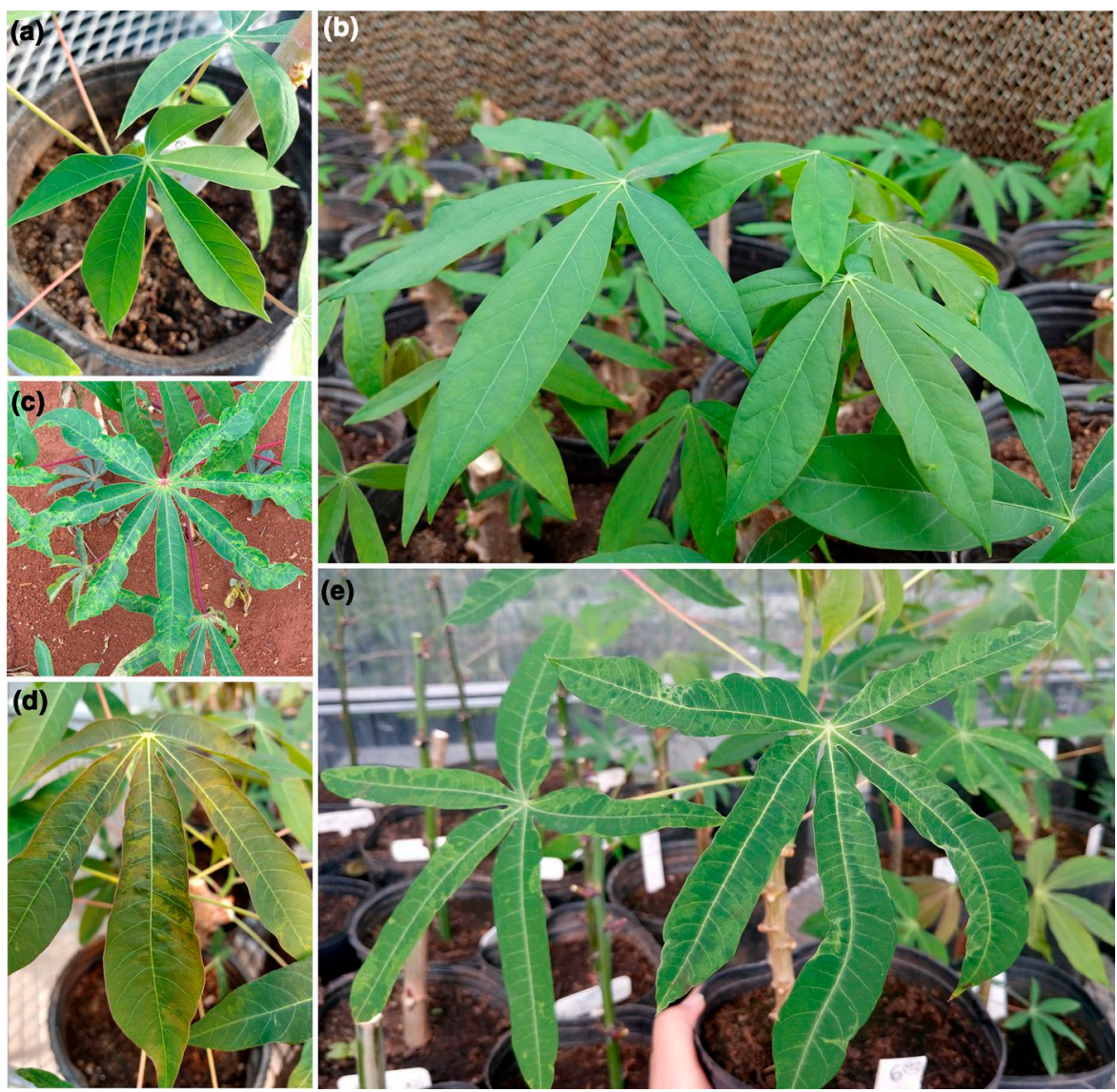

FIGURE 1 Plant material. (a, b) Healthy cassava plants (control). (c) Argentinian field-collected cassava plant showing cassava common mosaic disease symptoms. (d, e) CsCMV-infected cassava plants 90 days after planting (DAP), showing mosaic leaf symptoms with alternating green and yellow patches. Representative plants were used for pictures 

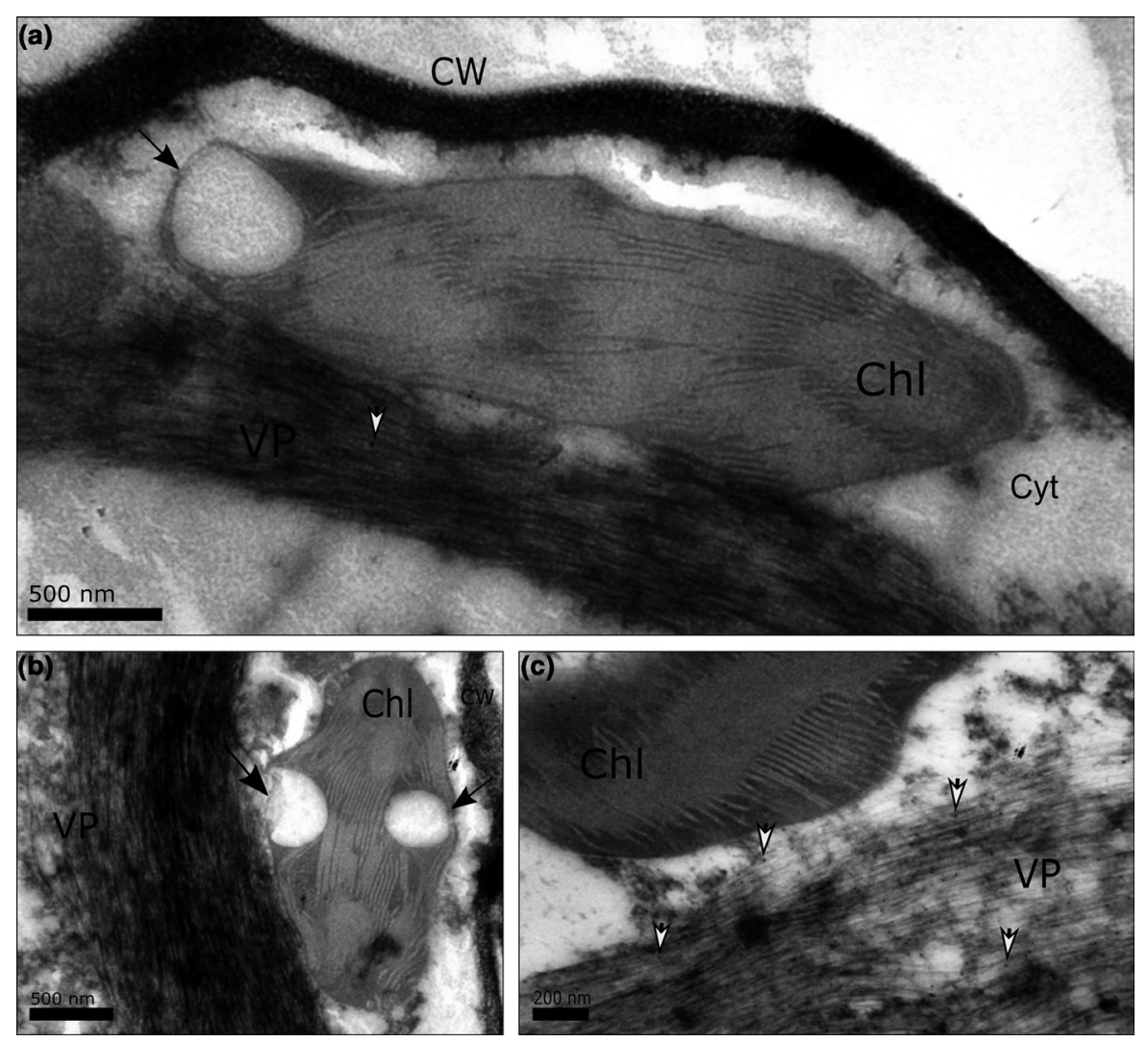

FIGURE 2 Ultrastructure of chloroplasts from CsCMV-infected mesophyll cassava cells. Transmission electron micrographs of a small sample $(0.2 \mathrm{~cm}$ wide $\times 0.5 \mathrm{~cm}$ long) slice from the middle part of leaf tissues from CsCMV-infected cassava plants. Leaf samples were prepared for transmission electron microscopy and the capsid protein immunogold labelling of CsCMV was performed as described in Section 2. (a, c) Capsid protein gold particle deposits (white head arrows) were located in cytoplasm around chloroplasts (Chl), where virus particles (VP) were present. CW, cell wall; Cyt, cytoplasm. (a, b) Black arrows indicated chloroplast malformations, such as small vesicles or vacuoles in stroma. Bar $=500 \mathrm{~nm}(\mathrm{a}, \mathrm{b})$ and $200 \mathrm{~nm}(\mathrm{c})$

progressed. Such changes occurred due to the reduction of maximum $\left(F_{m}\right)$ ChIF emission, which showed negative changes at the three stages (17\%, $9 \%$, and $11 \%$ at 60,75 , and 90 DAP, respectively). Indeed, a significant decrease in the $F_{v} / F_{0}$ ratio was found at the late stage (13\%). The energy flow taking place at the reaction centres (RC) was also altered by the CsCMV infection. Such event begins at light absorption (ABS) by PS II antenna pigments and ends at reduction of the end electron acceptors at the photosystem I (PS I) electron acceptor side (RE) driven by PS I. Then, changes in the size of the antenna complex $\left(\mathrm{ABS}_{\mathrm{O}} / \mathrm{RC}\right)$ and energy capture $\left(T R_{o} / R C\right)$ took place in infected plants with respect to control ones. Indeed, $A B S_{0} / R C$ increase started at 60 DAP (13\%) and rose to an average of $20 \%$ at 75 and 90 DAP. Moreover, $T_{\mathrm{o}} / \mathrm{RC}$ increased by $16 \%$ throughout all the stages in the infected plants (Figure 3). In turn, energy loss as latent heat ( $\mathrm{DI}_{\mathrm{o}} / \mathrm{RC}$ ) progressively increased, ranging from $26 \%$ at 60 DAP to $39 \%$ at 90 DAP. PS I electron acceptor side $\left(R_{0} / R C\right)$ showed a tendency to increase, which was not significant (10\% to $15 \%$ ). The performance index on absorption basis $\left(\mathrm{PI}_{\text {abs }}\right.$ ) of infected plants reduced on average by $33 \%$ with respect to noninfected plants at 75 and 90 DAP. Likewise, regarding the total performance index $\left(\mathrm{PI}_{\text {total }}\right)$, the effect of the virus was already observed at 60 DAP (34\%). The variable fluorescence at the $J$ stage $\left(V_{j}\right.$, occurring at $\left.2 \mathrm{~ms}\right)$ of the induction curve increased significantly at 60 and 90 DAP (11\%), whereas the area above the induction curve (Area) showed differences from the control at the three stages (15.3\%, 16.7\%, and 6.4\% at 60, 75, and 90 DAP, respectively). Chlorosis symptoms in cassava-infected leaves were assessed by the SPAD index. The SPAD value showed a $35 \%$ decrease at 60 DAP, $31 \%$ at 75 DAP, and $28 \%$ decrease at 90 DAP in CsCMV-infected plants with respect to noninfected ones (Figure 3b; Table S2). As a consequence of chloroplast damage and the energetic imbalance at the PS II electron transport, reducing power for photosynthesis was reduced. This result may explain the reduction of the photosynthetic rate observed 90 and 210 DAP (13.5\%-24.2\%, respectively; Figure 3a).

The differences of the normalized ChIF curves $\left(\Delta \mathrm{W}_{\mathrm{OK}}\right.$ and $\left.\Delta \mathrm{W}_{\mathrm{OI}}\right)$ revealed the appearance of hidden steps, such as the $\mathrm{K}$ and $L$ bands (OLKJIP). Positive bands ( $K$ band) occurring at about $300 \mu$ s are considered to denote failure at the OEC during 60, 75, and 90 DAP in CsCMV-infected plants (inset Figure 3c). Moreover, the fluorescence rise during the first $150 \mu$ s (Lband) is attributed to the loss of energetic connectivity between PS II units (Kalaji et al., 2016). Here, the appearance of $L$ band increased from 60 to 90 DAP (inset Figure 3d). 

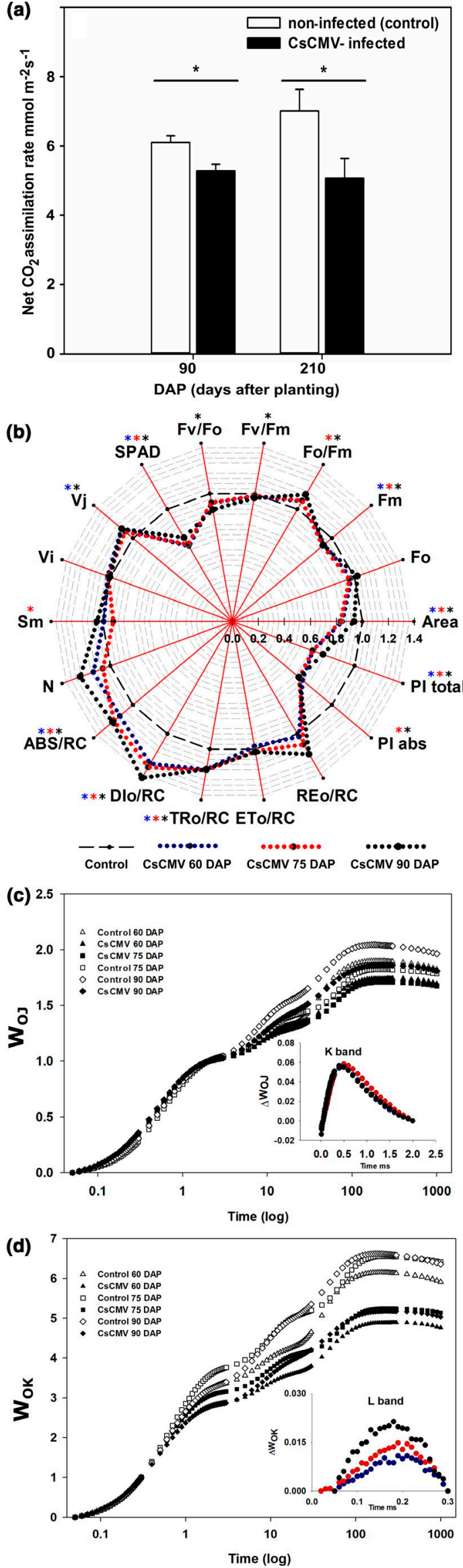

FIGURE 3 PS II activity and $\mathrm{CO}_{2}$ fixation in CsCMV-infected leaves. (a) Photosynthetic rates of noninfected (control) and CsCMV-infected cassava plants at two growth stages, 90 and 210 days after planting (DAP). (b) Radar plot showing OJIP test parameters in cassava control plants and CsCMV-infected plants. Measurements were carried out at 60 (blue), 75 (red), and 90 (black) DAP. Parameter abbreviations are described in Table S1. (c) Changes in the oxygen evolving complex (OEC, $\mathrm{K}$ band) and (d) energetic connectivity of PS II units ( $L$ band) in noninfected (empty icons) and CsCMV-infected cassava plants (filled icons). (c, inset panel) WOJ: normalized fluorescence kinetics from $\mathrm{O}(50 \mu \mathrm{s})$ to $\mathrm{J}$ step (2 ms). $\Delta$ WOJ $=$ WOJ $_{(\text {Treated })}-$ WOJ $_{(\text {Control) }}$, kinetics difference between treated and control plants, revealing the $\mathrm{K}$ band. (d, inset panel) WOK; normalized fluorescence kinetics from O $(50 \mu \mathrm{s})$ to $\mathrm{K}$ step $(300 \mu \mathrm{s}) . \Delta \mathrm{WOK}=\mathrm{WOK}_{\text {(Treated) }}-\mathrm{WOK}_{(\text {Control) }}$; kinetics difference between treated and control plants, revealing the Lband at 60 (blue), 75 (red), and 90 (black) DAP

\subsection{CsCMV infection and redox imbalance in cassava plants}

The FRAP assay offers a putative index of antioxidant or reducing state. An indirect estimation of the total nonenzymatic antioxidant content of the extract showed significant differences between the means of CsCMV-infected plants $(27.94 \pm 5.17 \mu \mathrm{mol} / \mathrm{g} \mathrm{FW})$ and the control plants ( $35.3 \pm 5.47 \mu \mathrm{mol} / \mathrm{g} \mathrm{FW}$; Figure 4). The reduction of the antioxidant capacity was about $20.8 \%$ in virus-infected plants.

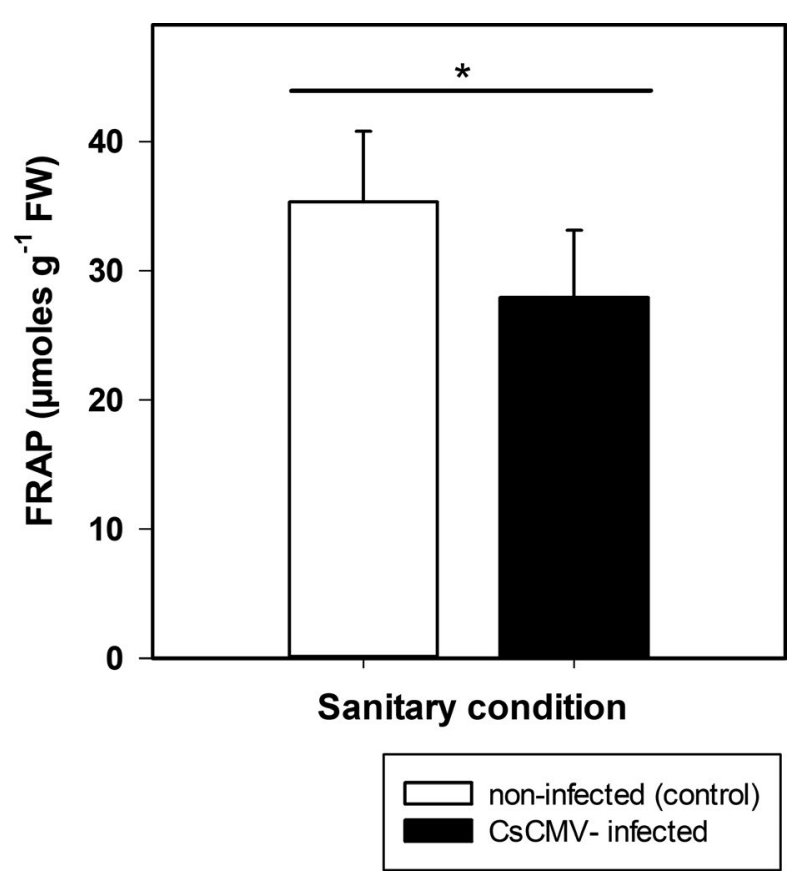

FIGURE 4 Antioxidant system in CsCMV-infected leaves. FRAP was measured in cassava leaves at 90 days after planting (DAP). Means of noninfected (white bars) and CsCMV-infected (black bars) plants. FW, fresh weight. *Statistically significant according to analysis of variance followed by Fisher LSD test $(p<.05, n=30)$ 


\subsection{Effects of CsCMV infection on carbohydrate and starch accumulation}

Starch content in infected cassava source leaves decreased significantly with respect to the control (Figure 5a). The mean value of starch content for control plants was $32.31 \pm 4.64 \mathrm{mg} / \mathrm{g} \mathrm{FW}$ and for CsCMV-infected plants was $24.95 \pm 4.59 \mathrm{mg} / \mathrm{g} \mathrm{FW}$. Total soluble sugar content was not significantly influenced in CsCMVinfected leaves $(30.19 \pm 2.90 \mathrm{mg} / \mathrm{g} \mathrm{FW})$ in contrast to noninfected $(29.52 \pm 2.91 \mathrm{mg} / \mathrm{g} \mathrm{FW}$; Figure 5b). Furthermore, AGPase activity was also not affected in CsCMV-infected leaves $(1.07 \pm 0.2 \mathrm{U}$ per $\mathrm{mg}$ protein) with respect to control plants $(1.01 \pm 0.21 \mathrm{U}$ per $\mathrm{mg}$ protein; Figure $5 c$ ).

A highly detailed profile of soluble sugars measured by HPLC showed a decrease of $16.5 \%$ in maltose content without significant differences in fructose, glucose, or sucrose in CsCMV-infected leaves with respect to control plants (mean values in Table 1). The sucrose:starch ratio showed a significant increase (24.7\%) with respect to noninfected plants (Table 1).

\section{4 | DISCUSSION}

Cassava-CsCMV compatible viral infection causes 30\%-60\% yield reduction of cassava roots (Venturini et al., 2016; Zanini et al., 2020). These yield losses reflect the final result of a series of physiological events that occur at earlier stages of viral interaction. The present study was focused on chloroplast morphological alteration and functional effects on source leaves during the course of viral infection. The mosaic symptoms induced by $\mathrm{CsCMV}$ were associated with structural changes of chloroplasts, decrease in relative $\mathrm{Chl}$ content, electron transport rate alteration, photoinhibition, reduction of $\mathrm{CO}_{2}$ fixation, reduction of starch, and maltose accumulation associated with increase in sucrose:starch ratio and drop of total antioxidant content.
CsCMV infection altered elongation rates; indeed, a higher elongation was observed at 75-90 DAP, which was not coupled with an increase in the number of nodes and leaves per bud over time; then, a decline of growth rate was observed (90-210 DAP). Thus, the alteration of the elongation rate in infected plants could be related to a metabolic source-sink imbalance, which might lead to a lower final height and consequent root yield losses in infected plants (Venturini et al., 2016; Zanini et al., 2020). In addition, we cannot rule out a hormonal disorder in infected plants.

The interaction between chloroplast and the invading virus plays a critical role in viral infection and pathogenesis (Zhao et al., 2016). Our previous results showed inclusion bodies of fibrous masses containing filamentous particles in the cellular cytoplasm near the chloroplast membrane (Zanini et al., 2014). In the present study, which was focused on chloroplast structure, we observed extrusion of the chloroplast membrane with amoeboid-shaped appearance, among other results, in CsCMV-infected leaves. Several research works have shown that viruses can interact with chloroplast proteins and induce the formation of membrane vesicles during viral replication, which impairs chloroplast function in plants (Liu et al., 2014; Li et al., 2016a; Zhao et al., 2016; Souza and Carvalho, 2019). For example, high levels of potato virus $X(P V X)$ coat protein $(C P)$ caused structural alteration of the chloroplast membranes, thylakoid grana, and invagination of the cytoplasm within these organelles; it was also found to interact with the plastocyanin (Zhao et al., 2016).

The development of mosaic symptoms induced by CsCMV was not only a consequence of the chloroplast structure alteration in cassava mesophyll cells, but also severely inhibited its function. Our results agree with findings of Liu et al. (2014), who reported that visible symptoms of chlorosis in cassava plants infected with African cassava mosaic virus (ACMV) were associated with chlorophyll breakdown (reduction of chlorophyll content and fewer grana stacks) and up-regulation of chlorophyll degradation genes. For a long time, the chloroplast-virus interaction has been a matter of debate due to its
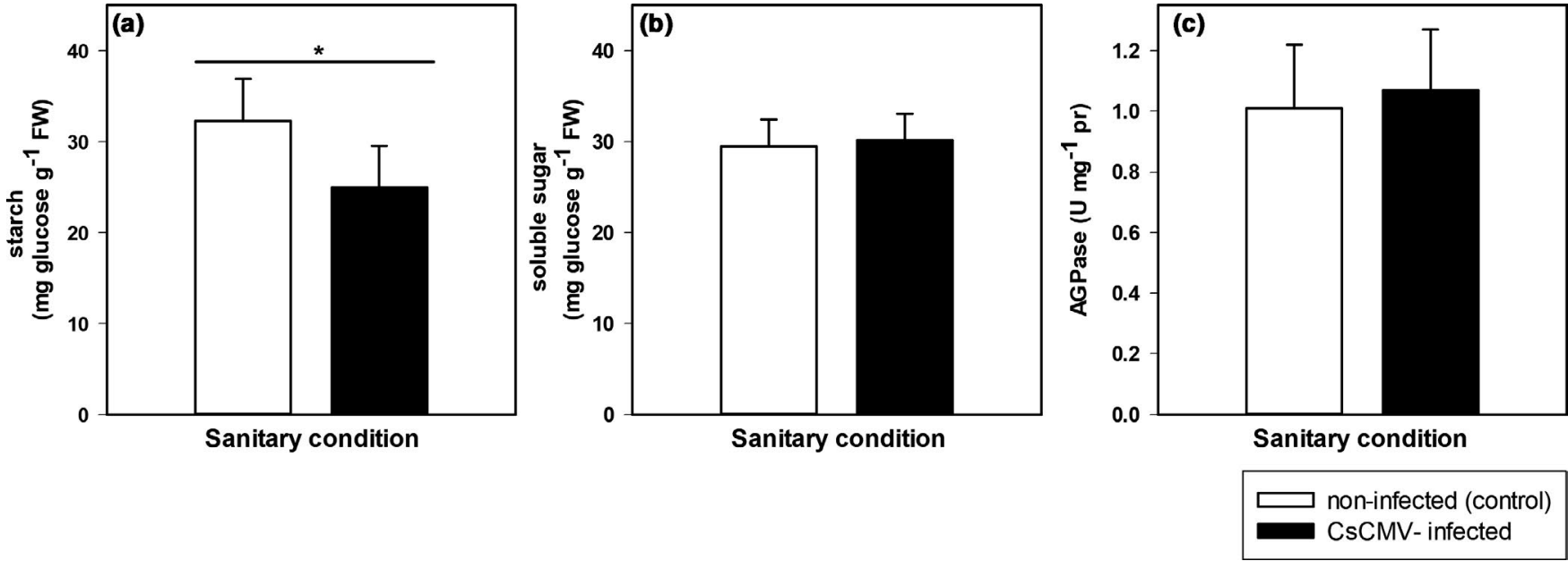

FIG URE 5 Carbon metabolism on cassava-CsCMV interaction at 90 days after planting (DAP). (a) Starch and (b) total soluble sugar content ( $n=30$ for each sanitary condition). (c) AGPase activity of cassava leaves of two sanitary conditions $(n=40)$. FW, fresh weight; pr, protein. * Statistically significant according to analysis of variance followed by Fisher LSD test $(p<.05)$ 
TAB LE 1 Sugar profile (mg/g fresh weight) on CsCMV-infected leaves at 90 days after planting

\begin{tabular}{llllll} 
Source leaves & Fructose & Glucose & Sucrose & Maltose* $^{*}$ & Sucrose:starch $^{* *}$ \\
\hline Noninfected (control) & $0.87 \pm 0.16$ & $2.29 \pm 0.15$ & $17.99 \pm 1.1$ & $4.73 \pm 0.39$ & $0.58 \pm 0.11$ \\
CsCMV-infected & $1.02 \pm 0.16$ & $2.28 \pm 0.12$ & $18.02 \pm 0.78$ & $3.95 \pm 0.22$ & $0.77 \pm 0.11$ \\
\hline
\end{tabular}

Note: Results are means of sugar contents obtained by HPLC of 20 plants of each sanitary condition \pm SE. Statistically significant according to analysis of variance followed by LSD Fisher test at ${ }^{* *} p<.05$; $^{*} p<.1$.

complexity. We noticed that CsCMV infection negatively affected the $\mathrm{CO}_{2}$ gas exchange rate, with a constant fall over the progress of the disease. This phenomenon could be explained by the lower production of ATP and NADPH, due to the closure of RC, as indicated by the increment in $A B S_{o} / R C$ values. On the other hand, virus infection could have reduced the carboxylation capacity through impairment of RuBisCO activity (Andreola et al., 2019).

According to the analysis of ChIF signals, CsCMV showed a severe impact on several events taking place on the PS II electron transport. The loss of PS II electron transport efficiency is regarded as a common phenomenon under biotic stress. As expected, the OJIPtest showed significant changes in most of the ChIF parameters over time in CsCMV-infected plants in relation to healthy ones. For instance, the viral infection decreased the photochemical efficiency of PSII $\left(F_{\mathrm{v}} / F_{\mathrm{m}}\right)$ at $90 \mathrm{DAP}$, whereas it increased light energy dissipation ( $\mathrm{DI}_{\mathrm{o}} /$ $\mathrm{RC})$ significantly, and decreased performance index $\left(\mathrm{PI}_{\mathrm{abs}}\right)$ and alteration in the linear electron transport $\left(E T_{\mathrm{o}} / \mathrm{RC}\right)$ in $\mathrm{PS} I \mathrm{II} . \mathrm{F}_{\mathrm{v}} / \mathrm{F}_{\mathrm{m}}$ has long been widely used as an indicator of photochemical damage or photoinhibition, mainly due to the inhibition of PS II centres, which are continuously repaired via degradation and synthesis of the D1 protein (Strasser et al., 2004; Rodríguez et al., 2010). The OJIP analysis showed that CsCMV had a strong impact on the performance index on an equal chlorophyll (absorption) basis ( $\mathrm{PI}_{\text {abs }}$ ). These findings are in agreement with other studies on abiotic stress, which showed that $\mathrm{PI}_{\text {asb }}$ responded promptly to the treatments, whereas $F_{\mathrm{v}} / F_{\mathrm{m}}$ was almost unchanged (Christen et al., 2007; Oukarroum et al., 2007; Živčák et al., 2008). This different response is because in its calculation, $\mathrm{PI}_{\mathrm{abs}}$ integrates three aspects of PS II of both composition and function, such as the density of fully active RCs, the efficiency of electron movement by trapped exciton into the electron transport chain beyond the $Q_{A}$, and the probability that an absorbed photon will be trapped by RCs (Strasser et al., 2004). Regarding the total performance index $\left(\mathrm{PI}_{\text {total }}\right)$, the effect of CsCMV was observed even at $60 \mathrm{DAP}$, indicating that damage by CsCMV was extended to the quantum efficiency of reduction of PS I end acceptors (analogous to $\mathrm{RE}_{\mathrm{o}} / \mathrm{RC}$; Redillas et al., 2011). Moreover, the specific fluxes expressed by RCs, such as the absorption, trapping, dissipation, and transport, denoted here as $A B S_{0} / R C$, $\mathrm{TR}_{\mathrm{o}} / \mathrm{RC}, \mathrm{DI}_{\mathrm{o}} / \mathrm{RC}$, and $\mathrm{ET}_{\mathrm{o}} / \mathrm{RC}$, respectively, indicated that the mechanisms of capture and dissipation of energy were effectively regulated, mainly by regulating the antenna size $\left(\mathrm{ABS}_{0} / \mathrm{RC}\right)$, and loss of energy as latent heat ( $\mathrm{DI} / \mathrm{RC}$ ). Oxygen evolving complex (OEC), a $\mathrm{Mn}_{4} \mathrm{O}_{5} \mathrm{Ca}$ protein cluster embedded in the PS II, is essential in the photosynthesis process. It has been demonstrated that the viral CP, or some other products synthesized as a result of the viral infection, decreases the amount of OEC polypeptides, as reported in tobacco leaves infected with CMV strain Y (Takahashi and Ehara, 1992). In our work, a progressive loss of OEC activity was revealed by the Kband starting 60 DAP in CsCMV-infected leaves. Under particular stressful conditions, the Kband was demonstrated to indicate a disruption of the OEC (Kalaji et al., 2016). Likewise, the OJIP analysis showed that the slope between $\mathrm{F}_{\mathrm{o}}$ and $\mathrm{F}_{150}$ (Lband) was sensitive to the CsCMV attack, which progressively increased up to 90 DAP. This phenomenon occurs due to a loss of connectivity within the tripartite system (core antenna-LHCll-reaction centre) under particular abiotic stress conditions (Strasser et al., 2004; Kalaji et al., 2016); here it is reported for a virus infection for the first time.

The virus ability to impair chloroplast function and disrupt the photosynthetic electron transport chain ultimately leads not only to the decrease of the carboxylation activity, but also to ROS increase (Rodríguez et al., 2010, 2012; Souza et al., 2019). CsCMV induced redox alteration, demonstrated by the lower antioxidant capacity (FRAP), indicating an oxidative stress process. Furthermore, the $\mathrm{CO}_{2}$ fixation decrease might be directly related to soluble sugar production. Nuwamanya et al. (2017) demonstrated that cassava brown streak disease, caused by potyviruses, leads to a general reduction in primary carbohydrate composition (total reducing sugar and starch contents) in leaves; these effects correlated with the negative effect on the photosynthetic apparatus of infected leaves. However, our results did not show such significant differences in the total soluble sugar contents in CsCMV-infected source leaves with respect to noninfected plants. The differences between results might be related to the specific source tissue analysed during our work. These results led us to ask about the origin of these sugars, because photosynthetic activity was decreased by viral infection. One possible answer might be related to the findings of Sharkey et al. (1985) that, at low rates of photosynthesis, carbon would preferably be used for sucrose synthesis rather than for storage in starch form. Accordingly, the present study showed a rise in the ratio of carbon partitioned into sucrose versus starch in CsCMV-infected plants. Another possible answer may be starch breakdown, which provides a source of reduced carbon when photosynthesis cannot occur. Indeed, starch content was decreased during viral infection. However, maltose, which might be increased in leaves when starch catabolism is induced, showed a significant decrease in CsCMV-infected leaves. In this context, we cannot rule out the fast maltose metabolism for viral replication. Moreover, the different sugars might be finely sensed and might provide a mechanism to conduct carbon flux during viral infection (Sade et al., 2013; Hulsmans et al., 2016). Besides metabolic flux diversion, another possible source of soluble sugar could be related to alteration of sugar transporters, which convert these 
source leaves into sink tissues, or a gluconeogenesis process induction (Rodríguez et al., 2010). These possible sugar sources are not mutually exclusive but might be operating in combination, and have to be explored in future studies.

To conclude, cassava produces storage roots, which are the major sink for storing starch derived from carbohydrate partitioning and long-distance sugar transport from the leaves (Yan et al., 2019). The early alterations in photosynthesis and chloroplast structure observed during the present work might be related to negative impact on yield previously observed at a later stage (Zanini et al., 2020). Such changes imply smaller reserve roots, that is, fewer accumulated carbohydrates. Therefore, understanding the metabolic alteration induced by $\mathrm{CsCMV}$ in source leaves at this early stage is critical for improving cassava yield. This is the first report demonstrating physiological alterations associated with chloroplast ultrastructure and function in the cassava-CsCMV pathosystem.

\section{ACKNOWLEDGEMENTS}

We are grateful to Claudia Nome and Leandro Ortega for helpful assistance in electron microscopy and HPLC techniques, respectively. We thank Edith Taleisnik for comments on the manuscript and helpful discussions. This work was supported by grants from the Agencia de Promoción Científica y Tecnológica, Argentina (PICT-2014-551), and the Instituto Nacional de Tecnología Agropecuaria (INTA-I085). A.A.Z., P.P., and A.C. are fellows and M.R. is a researcher of CONICET (Consejo Nacional de Investigaciones Científicas y Técnicas, Argentina). M.R., F.D.L., and L.D.F. are researchers of INTA.

\section{CONFLICTS OF INTEREST}

No potential conflicts of interest are disclosed.

\section{AUTHOR CONTRIBUTIONS}

M.R. and A.A.Z. designed the experiments. A.A.Z. conducted the experiments. A.A.Z. and M.R. took the measurements. A.C. carried out in vitro culture and acclimatization of cassava seedlings. L.D.F. contributed with cassava plants and virus detection. D.F.L. contributed in the fluorescence analysis. A.A.Z. and P.P. performed the statistical analysis of data. A.A.Z. and M.R. drafted and cowrote the manuscript. A.A.Z., L.D.F., D.F.L., and M.R. contributed with the discussion and editing of the manuscript. M.R. conceived and supervised the project.

\section{DATA AVAILABILITY STATEMENT}

The data that support the findings of this study are available from the corresponding author upon reasonable request.

\section{ORCID}

Andrea A. Zanini (iD https://orcid.org/0000-0002-2936-5850

Marianela S. Rodriguez iD https://orcid.org/0000-0003-4869-004X

\section{REFERENCES}

Andreola, S., Rodriguez, M., Parola, R., Alemano, S. and Lascano, R. (2019) Interactions between soybean, Bradyrhizobium japonicum and Soybean mosaic virus: the effects depend on the interaction sequence. Functional Plant Biology, 46, 1036.

Benzie, I.F.F. and Strain, J.J. (1996) The ferric reducing ability of plasma (FRAP) as a measure of "antioxidant power": the FRAP assay. Analytical Biochemistry, 239, 70-76.

Bradford, M.M. (1976) A rapid and sensitive method for the quantitation of microgram quantities of protein utilizing the principle of protein-dye binding. Analytical Biochemistry, 72, 248-254.

Calvert, L.A., Cuervo, M. and Lozano, I. (2012) Cassava viral disease in South America. In: Ospina, B. and Ceballos, H. (Eds.) Cassava in the Third Millennium: Modern production, Processing, Use and Marketing Systems. Cali, Colombia: CIAT, pp. 309-318.

Chaparro-Martinez, E.I. and Trujillo-Pinto, G. (2003) Enfermedades virales en el cultivo de yuca (Manihot esculenta Crantz) en algunos estados de Venezuela. Revista Facultad Agronomía, 20, 461-467.

Chen, S., Yang, J., Zhang, M., Strasser, R.J. and Qiang, S. (2016) Classification and characteristics of heat tolerance in Ageratina adenophora populations using fast chlorophyll a fluorescence rise O-JI-P. Environmental and Experimental Botany, 122, 126-140.

Christen, D., Schönmann, S., Jermini, M., Strasser, R.J. and Défago, G. (2007) Characterization and early detection of grapevine (Vitis vinifera) stress responses to esca disease by in situ chlorophyll fluorescence and comparison with drought stress. Environmental and Experimental Botany, 60, 504-514.

Di Rienzo, J.A., Casanoves, F., Balzarini, M.G., Gonzalez, L., Tablada, M. and Robledo, C.W. (2019) InfoStat version 2019. Córdoba, Argentina: Grupo InfoStat, FCA, Universidad Nacional de Córdoba.

Fales, F.W. (1951) The assimilation and degradation of carbohydrates by yeast cells. Journal of Biological Chemistry, 193, 113-124.

FAO. (2013) Save and Grow: Cassava. A Guide to Sustainable Production Intensification. Rome: FAO. Available at: http://www.fao.org/3/ai3278e.pdf. [Accessed 11 September 2020].

Fernandez, E., Espinoza, I., Lozano, I., Bolaños, C., Carvajal-Yepes, M. and Cuellar, W.J. (2017) First report of cassava common mosaic disease and Cassava common mosaic virus infecting cassava (Manihot esculenta) in Peru. Plant Disease, 101, 1066.

Hulsmans, S., Rodriguez, M., De Coninck, B. and Rolland, F. (2016) The SnRK1 energy sensor in plant biotic interactions. Trends in Plant Science, 21, 648-661.

Kalaji, H.M., Jajoo, A., Oukarroum, A., Brestic, M., Zivcak, M., Samborska, I.A. et al. (2016) Chlorophyll a fluorescence as a tool to monitor physiological status of plants under abiotic stress conditions. Acta Physiologiae Plantarum, 38, 102.

Kulichikhin, K., Mukherjee, S. and Ayele, B. (2016) Extraction and assays of ADP-glucose pyrophosphorylase, soluble starch synthase and granule bound starch synthase from wheat (Triticum aestivum L.) grains. Bio-Protocol, 6, e1929.

Legg, J.P., Kumar, P.L., Makeshkumar, T., Tripathi, L., Ferguson, M., Kanju, E. et al. (2015) Cassava virus diseases: biology, epidemiology, and management. Advances in Virus Research, 91, 85-142.

Li, Y., Cui, H., Cui, X. and Wang, A. (2016a) The altered photosynthetic machinery during compatible virus infection. Current Opinion in Virology, 17, 19-24.

Li, Y.Z., Zhao, J.Y., Wu, S.M., Fan, X.W., Luo, X.L. and Chen, B.S. (2016b) Characters related to higher starch accumulation in cassava storage roots. Scientific Reports, 6, 19823.

Liu, J., Yang, J., Bi, H. and Zhang, P. (2014) Why mosaic? Gene expression profiling of African cassava mosaic virus-infected cassava reveals the effect of chlorophyll degradation on symptom development. Journal of Integrative Plant Biology, 56, 122-132.

Lozano, I., Leiva, A.M., Jimenez, J., Fernandez, E., Carvajal-Yepes, M., Cuervo, M. et al. (2017) Resolution of cassava-infecting alphaflexiviruses: molecular and biological characterization of a novel group of potexviruses lacking the TGB3 gene. Virus Research, 241 $53-61$. 
Marx, S. (2019) Cassava as feedstock for ethanol production: a global perspective. In: Ray, R.C. and Ramachandran, S. (Eds.) Bioethanol Production from Food Crops. London: Academic Press, pp. 101-113.

Maunsbach, A.B. and Afzelius, B.A. (1998) Biomedical Electron Microscopy: Illustrated Methods and Interpretations. San Diego, CA: Academic Press.

Nuwamanya, E., Baguma, Y., Atwijukire, E., Acheng, S., Abidrabo, P. Omongo, C.A. et al. (2017) Cassava brown streak disease effects on leaf metabolites and pigment accumulation. African Crop Science Journal, 25, 33-45.

Oukarroum, A., El, M.S., Schansker, G. and Strasser, R.J. (2007) Probing the responses of barley cultivars (Hordeum vulgare L.) by chlorophyll a fluorescence OLKJIP under drought stress and re-watering. Environmental and Experimental Botany, 60, 438-446.

Redillas, M.C.F.R., Jeong, J.S., Strasser, R.J., Kim, Y.S. and Kim, J.-K. (2011) JIP analysis on rice (Oryza sativa cv Nipponbare) grown under limited nitrogen conditions. Journal of the Korean Society for Applied Biological Chemistry, 54, 827-832.

Rodríguez, M., Muñoz, N., Lenardon, S. and Lascano, R. (2012) The chlorotic symptom induced by Sunflower chlorotic mottle virus is associated with changes in redox-related gene expression and metabolites. Plant Science, 196, 107-116.

Rodríguez, M., Taleisnik, E., Lenardon, S. and Lascano, R. (2010) Are sunflower chlorotic mottle virus infection symptoms modulated by early increases in leaf sugar concentration? Journal of Plant Physiology, 167, 1137-1144.

Sade, D., Brotman, Y., Eybishtz, A., Cuadros-Inostroza, A., Fernie, A.R., Willmitzer, L. et al. (2013) Involvement of the hexose transporter gene LeHT1 and of sugars in resistance of tomato to tomato yellow leaf curl virus. Molecular Plant, 6, 1707-1710.

Sharkey, T.D., Berry, J.A. and Raschke, K. (1985) Starch and sucrose synthesis in Phaseolus vulgaris as affected by light, $\mathrm{CO}_{2}$, and abscisic acid Plant Physiology, 77, 617-620.

Silva, J.M., Carnelossi, P.R., Bijora, T., Facco, C.U., Picoli, M.H.S., Souto, E.T. et al. (2011) Immunocapture-RT-PCR detection of Cassava common mosaic virus in cassava obtained from meristem-tip culture in Paraná state. Tropical Plant Pathology, 36, 271-275.

Souza, P.F.N. and Carvalho, F.E.L. (2019) Killing two birds with one stone: how do plant viruses break down plant defenses and manipulate cellular processes to replicate themselves? Journal of Plant Biology, 62, 170-180.

Souza, P.F.N., Garcia-Ruiz, H. and Carvalho, F.E.L. (2019) What proteomics can reveal about plant-virus interactions? Photosynthesisrelated proteins on the spotlight. Theoretical and Experimental Plant Physiology, 31, 227-248.

Strasser, R.J., Tsimilli-Michael, M. and Srivastava, A. (2004) Analysis of the chlorophyll a fluorescence transient. In: Papageorgiou, G.C. and Govindjee (Eds.) Chlorophyll a Fluorescence, a Signature of Phytosynthesis. Dordrecht: Springer, pp. 321-362.

Sumner, J.B. and Somers, G. (1944) The water-soluble polysaccharides of sweet corn. Archives of Biochemistry and Biophysics, 4, 7-9.

Takahashi, H. and Ehara, Y. (1992) Changes in the activity and the polypeptide composition of the oxygen-evolving complex in photosystem II of tobacco leaves infected with cucumber mosaic virus strain Y. Molecular Plant-Microbe Interactions, 5, 269-272.
Tascon, Â., Kitajima, E.W. and Costa, A.S. (1975) Microscopia electrônica do vírus do mosaico comum da mandioca nos tecidos foliares de diferentes plantas hospedeiras. Bragantia, 34, V-X.

Técsi, L.I., Smith, A.M., Maule, A.J. and Leegood, R.C. (1996) A spatial analysis of physiological changes associated with infection of cotyledons of marrow plants with cucumber mosaic virus. Plant Physiology, $111,975-985$.

Tuo, D.C., Zhao, G.Y., Yan, P., Li, R.M., Chen, X., Wang, W.Q. et al. (2020) First report of Cassava common mosaic virus infecting cassava in mainland China. Plant Disease, 104, 997.

Venturini, M.T., Araújo, T.daS., Abreu, E.F.M., Andrade, E.C.d., Santos, V.daS., Silva, M.R.d. et al. (2016) Crop losses in Brazilian cassava varieties induced by the Cassava common mosaic virus. Scientia Agricola, 73, 520-524.

Yan, W., Wu, X., Li, Y., Liu, G., Cui, Z., Jiang, T. et al. (2019) Cell wall invertase 3 affects cassava productivity via regulating sugar allocation from source to sink. Frontiers in Plant Science, 10, 541.

Zanini, A., Collavino, A., Medina, R., Celli, M., Conci, V. and Di Feo, L. (2020) Influencia de Cassava common mosaic virus (CsCMV) en la producción de raíces de plantas de Manihot esculenta. Revista Investigación, Ciencia y Universidad, 3, 99.

Zanini, A.A., Cuellar, W.J., Celli, M.G., Luque, A.V., Medina, R.D., Conci, V.C. et al. (2018) Distinct strains of the re-emergent Cassava common mosaic virus (genus: Potexvirus) infecting cassava in Argentina. Plant Pathology, 67, 1814-1820.

Zanini, A., Rodríguez Pardina, P., Luque, A. and Di Feo, L. (2014) Identificación y caracterización de Cassava common mosaic virus en cultivos de mandioca en Argentina. Revista Ciencia y Tecnología de los Cultivos Industriales, 4, 31-38.

Zhao, J., Zhang, X., Hong, Y. and Liu, Y. (2016) Chloroplast in plant-virus interaction. Frontiers in Microbiology, 7, 1565.

Živčák, M., Brestič, M., Olšovská, K. and Slamka, P. (2008) Performance index as a sensitive indicator of water stress in Triticum aestivum L. Plant, Soil and Environment, 54, 133-139.

\section{SUPPORTING INFORMATION}

Additional supporting information may be found online in the Supporting Information section.

How to cite this article: Zanini AA, Di Feo L, Luna DF, Paccioretti P, Collavino A, Rodriguez MS. Cassava common mosaic virus infection causes alterations in chloroplast ultrastructure, function, and carbohydrate metabolism of cassava plants. Plant Pathol. 2020;00:1-11. https://doi. org/10.1111/ppa.13272 